\title{
ANÁLISIS NORMATIVO CRÍTICO DE LA REGLA FISCAL EN CHILE
}

\section{CRITICAL REGULATORY ANALYSIS OF THE FISCAL RULE IN CHILE}

\author{
Jaime R. Gallegos ZúNiga ${ }^{1}$
}

\begin{abstract}
RESUMEN: La ley No 20.128, de responsabilidad fiscal, de 2006, ha estado ajena al análisis por parte de las ciencias jurídicas durante su vigencia, no obstante la relevancia de la materia. Con ocasión del deterioro de la posición fiscal del país, urge indagar y exponer sus elementos centrales y proponer cambios que permitan retornar el rumbo hacia un manejo ordenado de las arcas públicas.
\end{abstract}

Palabras clave: Finanzas públicas, responsabilidad fiscal, fondos soberanos, regla fiscal

ABSTRACT: Fiscal Responsibility Law No 20,128 (2006), has not been analyzed by the legal sciences during its validity, notwithstanding the relevance of the matter. With the deterioration of the fiscal position of the country, it is urgent to investigate and expose its central elements and propose changes that allow the return to the direction towards an orderly management of public coffers.

Keywords: Public finance, fiscal responsibility, sovereign funds, fiscal rule

\section{ASPECTOS GENERALES}

La baja en la clasificación de riesgo del país demanda que, desde las ciencias jurídicas se analice la institucionalidad de las finanzas públicas. Por ello, nos parece que es relevante para el momento actual, estudiar la ley No 20.128, sobre responsabilidad fiscal, y evaluar los cambios que en esta preceptiva deben practicarse, con el objeto de retomar la senda de sanidad de la hacienda.

En primer término, es necesario advertir que la Constitución de 1980 no contempla una regla fiscal o un mandato imperativo que impida se presenten presupuestos deficitarios. Tampoco lo preveía la Carta de 1925, y en efecto, entre 1950 y 1986, en promedio, las cuentas fiscales exhibieron un déficit del 1,9\% del Producto Interno Bruto (en adelante, (PIB) $)^{2}$.

No obstante esa carencia, el Texto de 1980 alberga diferentes disposiciones conducentes a un manejo ordenado de la $\mathrm{Hacienda}^{3}$, con una preponderancia del Ejecutivo y

1 Máster en estudios avanzados en Derecho Financiero y Tributario de la Universidad Complutense de Madrid. Profesor de Políticas Económicas de la Facultad de Derecho de la Universidad de Chile. Dirección postal: Facultad de Derecho de la Universidad de Chile, Departamento de Derecho Económico, Pío Nono No 1, cuarto piso, Providencia, Chile. Dirección electrónica: jgallegos@derecho.uchile.cl

2 Arellano (2006) pp. 166-167.

3 Endress (2009) p. 110; Obando (1994) p. 544; YrarráZaVAl (1987) pp. 109-111. 
atribuciones acotadas del Legislativo ${ }^{4}$, como consecuencia, según se ha dicho, que la Constitución previa reconociera muchas prerrogativas al Parlamento, que fueron indebidamente ejercidas, en perjuicio del ordenado manejo de las cuentas fiscales 5 .

En efecto, el Tribunal Constitucional, en Sentencia del Tribunal Constitucional (en adelante, STC) STC No 254, de 1997, en su considerando 21 aseveró que "es un hecho que la Ley de Presupuestos disminuye las atribuciones legislativas del Congreso y amplía las facultades colegisladoras del Presidente de la República", lo que constituye "una de las manifestaciones del vigoroso presidencialismo consagrado en la Constitución de 1980" (considerando 23), ideas que, se reafirmarían luego en los considerandos 28 y 30 de la STC No 1.867 , de 2010 .

A su turno, de diferentes disposiciones que integran la Carta Fundamental ${ }^{6}$, un sector de la doctrina ${ }^{7}$ ha alzado al principio de equilibrio presupuestario, como eje rector de las finanzas públicas.

También es conveniente acotar que el Tribunal Constitucional ha sostenido que el equilibrio es un principio presupuestario (STC No 1.867, de 2010, en su considerando 30), manifestando que "los gastos deben corresponder a los ingresos, sin que pueda haber gastos desfinanciados", aseveración, que, sin embargo, ha sido expuesta sin fundamentar normativamente lo enunciado.

Hechas estas aclaraciones previas, corresponde expresar que la seriedad en el manejo de los recursos públicos fue una regla básica que orientó a las autoridades de las últimas décadas. En este sentido, es de destacar que durante las administraciones de los Presidentes Aylwin Azócar y Frei Ruiz-Tagle se optó por incurrir en gastos permanentes solo en el evento en que estuviesen asegurados los correspondientes ingresos de modo estable ${ }^{8}$, lo cual no fue óbice para un aumento ininterrumpido del gasto social ${ }^{9}$ atendido el positivo desempeño de la economía chilena durante la mayor parte de sus gobiernos.

En paralelo a ello, durante una buena fracción de la década de los noventa la política fiscal se llevó a cabo como si el objetivo de las autoridades fuera obtener un superávit estructural del $1 \%$ del PIB, aunque no se midiera, se conociera o se difundiera como tal ${ }^{10}$.

En este contexto, el año 2000, el Presidente Lagos Escobar anunció la implementación de una regla de superávit estructural en el manejo de la Hacienda Pública ${ }^{11}$, que descansaba en el referido superávit efectivo que se obtuvo, de manera casi ininterrumpida, en las administraciones anteriores ${ }^{12}$.

Con todo, debe advertirse que los años previos a la implementación de este régimen tuvo lugar la crisis asiática, que afectó fuertemente a la economía chilena, que en 1999

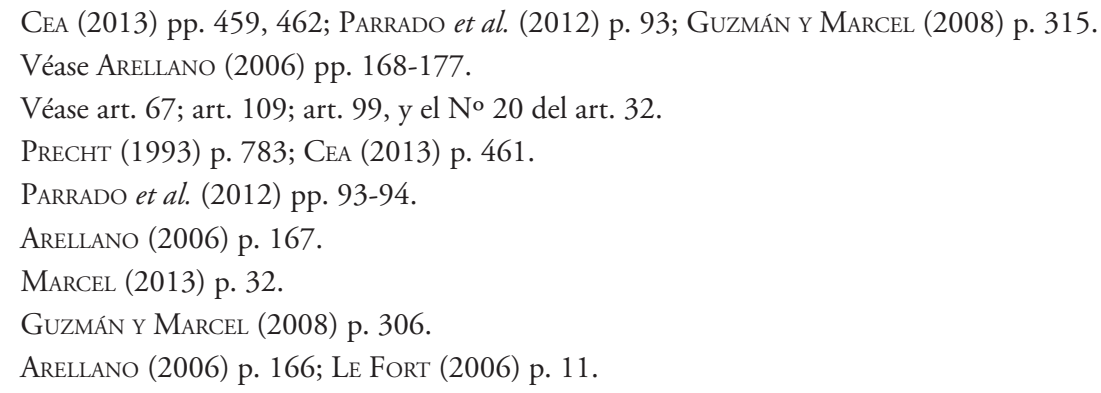


incurrió en un déficit del 2,5\% del PIB, motivo por el cual, para las autoridades entrantes, era necesario actuar con premura para evitar cuestionamientos a la conducción fiscal. La adopción de una regla fiscal implicaba, entonces, que el Presidente Lagos estaba dispuesto a renunciar, en cierta medida, a su control sobre la gestión de las finanzas públicas para aumentar la confianza de los agentes económicos ${ }^{13}$.

De este modo, ya a partir del presupuesto del año 2001, se comenzó a aplicar, por voluntad del Ejecutivo, sin exigencia legal alguna, esta regla que, con motivo de los positivos frutos que cosechó, fue respaldada por diferentes sectores ${ }^{14}$.

Con posterioridad la responsabilidad fiscal se institucionalizaría a través de la ley No $20.128^{15}$, de 2006, que le confirió tal rango al proyecto presentado en septiembre de 2005 , estableciendo metas explícitas en relación con los presupuestos, basadas en ingresos estructurales. Asimismo, esta ley crea dos fondos soberanos a los cuales se dirigen los recursos que se captan por aplicación de este mecanismo de disciplina de las finanzas públicas, el de Estabilización Económica y Social (FEES) y el de Reserva de Pensiones (FRP).

El proyecto de ley de la especie -que fue catalogado, en su oportunidad, por el entonces senador Camilo Escalona como "tal vez, el más importante que se haya aprobado en el Congreso Nacional en lo relativo a la configuración de una institucionalidad económica" (BCN, 2006, p. 160) y por el, en ese momento, diputado Rodrigo Álvarez como "uno de los más importantes que hemos discutido en el último tiempo para el crecimiento económico, para dar estabilidad, para mantener políticas sanas, desde el punto de vista macroeconómico" (BCN, 2006, p. 229)- recogió recomendaciones de evaluaciones externas sobre transparencia, realizadas por el FMI, el Banco Interamericano de Desarrollo (BID), el Banco Mundial (BM) y la Organización para Cooperación y Desarrollo Económico (OCDE) ${ }^{16}$, ajustadas a la realidad fiscal del país, como también los planteamientos de la propia Comisión Especial de Presupuestos del Congreso ${ }^{17}$, que venía estudiando la posibilidad de brindar ese rango normativo a esta materia.

La regla fiscal chilena, se dijo que era el "caso paradigmático"18 de la región, que a los pocos años de vigencia afrontó ambas fases del ciclo, desenvolviéndose favorablemente, motivo por el cual sirvió de referente para otros países ${ }^{19}$.

Luego, entrando a la implementación de la regulación misma, el art. 10 del decreto ley No 1.263, de 1975, Orgánico de Administración Financiera del Estado -con posterioridad a la modificación practicada por la referida ley No 20.128-, prevé que el Programa

13 Marcel (2013) p. 5.

14 García (2012) pp. 26, 31-35.

15 En el mensaje de la ley se indica que "El manejo ordenado y responsable de las finanzas públicas ha sido ampliamente reconocido como unos de los principales factores que explican los logros que hemos obtenido en los últimos quince años en crecimiento económico, reducción de la pobreza y desarrollo social. La responsabilidad fiscal, igualmente, es uno de los recursos fundamentales con que contamos como país para enfrentar los múltiples desafíos pendientes del desarrollo" (BCN, 2006, p. 3).

16 Pallavicini (2015) p. 78.

17 BCN (2006) pp. 53-54, 68.

18 JiMÉNEZ y LÓPEZ (2013) p. 29.

19 Velasco et al. (2010) p. 7; Frankel (2011) pp. 39, 41, 42, 64, 66; Ardanaz et al. (2015) pp. 12, 29; García (2012) pp. 26, 29, 31-35, 39; Marcel (2013) p. 2; Ter-Minassian (2011) p. 136. 
Financiero, como instrumento de planificación y gestión financiera de mediano plazo, comprende una estimación del Balance Estructural del Sector Público, sobre la base de la metodología, procedimientos y demás normas que "debiesen" estar establecidas mediante decreto supremo emanado del Ministerio de Hacienda, acto administrativo al cual le corresponde incluir la manera de recabar la opinión de expertos independientes sobre los factores que determinan el nivel de tendencia de los ingresos y gastos del Gobierno Central, así como la forma y oportunidad en que debe informarse el resultado de la estimación del referido Balance.

\section{ASPECTOS FUNCIONALES DE LA REGLA FISCAL CHILENA}

El balance estructural del sector público refleja el balance presupuestario que se produciría -fundamentalmente- si el producto evolucionara de acuerdo a su tendencia y si el precio del cobre fuese el de mediano plazo ${ }^{20}$.

Esta política colabora para que el Gobierno tenga espacio para ahorrar en tiempos de bonanza y aumente el gasto público en aquellos momentos de reducción de la actividad económica, permitiendo la implementación de medidas contracíclicas ${ }^{21}$.

Esta fórmula fue destacada dentro del continente como una innovación, puesto que los restantes países del área, a esa fecha habían configurado sus reglas fiscales utilizando límites numéricos en relación con el balance general primario público y/o de gasto público, sin atender a los ingresos estructurales o cíclicamente ajustados, logrando entonces un Balance Cíclico Ajustado (BCA) ${ }^{22}$.

El que los egresos se determinen de acuerdo con los ingresos estructurales permite que estos mantengan una trayectoria, y que no se vean mayormente afectados por las fluctuaciones cíclicas de las entradas efectivas, colaborando, de este modo, con la sostenibilidad del gasto público, permitiendo una mejor planificación del mismo ${ }^{23}$.

Por otra parte, es pertinente señalar que -dejando en claro cuál era la orientación y lo perseguido por el legislador cuando reguló esta materia- de acuerdo con el inciso primero del art. 20 de la ley No 20.128 se entiende por superávit efectivo el "superávit" resultante de la ejecución de ingresos y gastos del sector público en el año anterior, excluidos los ingresos originados por la rentabilidad que genere la inversión de los recursos del FRP.

A su turno, la meta de balance estructural es un porcentaje de los ingresos estructurales que debe tenerse en cuenta al confeccionar el presupuesto para un año dado. En sus comienzos, la aplicación de esta regla ubicó esa meta en el 1\% de los ingresos estructurales, sin embargo, ello fue cambiando con el correr del tiempo.

\footnotetext{
Velasco et al. (2007) p. 5.

21 Frankel (2011) p. 40; Velasco et al. (2010) p. 7; Marcel (2013) p. 25.

22 Berganza (2012) p. 307; Ter- Minassian (2011) pp. 122, 137.

23 Guzmán y Marcel (2008) p. 307; Ffrench-Davis (2016) p. 153; Larraín y Parro (2008) pp. 570, 571, 580, 581; Acevedo et al. (2014) pp. 42-46; Rodríguez y Flores (2010) pp. 1-26.
} 


\subsection{Formalización DE la postura (“COMPROMiso”) DEL GOBIERNO FRENTE A LA} REGLA DEL BALANCE ESTRUCTURAL

El Presidente de la República, dentro de los 90 primeros días de asumir sus funciones, debe establecer -con arreglo al art. $1^{\circ}$ de la ley No 20.128- "las bases de la política fiscal que se aplicará durante su administración", que debe incluir "un pronunciamiento explícito acerca de las implicancias y efectos que tendrá su política sobre el Balance Estructural" en su período al mando del país, a través de decreto, preanunciando las bases de la política fiscal en relación con la referida regla ${ }^{24}$.

Ahora bien, conviene precisar que ni la ley en cuestión ni otro cuerpo normativo obliga al Gobierno a adoptar una posición en torno a la regla fiscal, ni lo constriñe a cumplir con una meta cuantitativa puntual del balance cíclicamente ajustado.

Asimismo, la preceptiva enunciada consigna el deber de que copia del referido decreto, así como de "las modificaciones que se le introduzcan durante su vigencia", sean remitidos a las Comisiones de Hacienda del Senado y de la Cámara de Diputados, y a la Comisión Especial de Presupuestos.

Como puede apreciarse del tenor de esta norma, si bien se prevé la necesidad de que el Ejecutivo adopte un compromiso público y concreto frente a la regla fiscal que orientará su período gubernamental, se admite que a tal instrumento se le introduzcan modificaciones durante su vigencia.

\subsection{Decretos Dictados EN CUMPLIMIENTO DE LA NORMATIVA RESEÑADA}

El imperativo legal enunciado se ha cumplido a través de los decretos No 1.259 , de 2006; 637, de 2010, y 892, de 2014, todos del Ministerio de Hacienda, de los gobiernos de los Presidentes Bachelet, Piñera y Bachelet, respectivamente.

En particular, el decreto No 1.259 , de 2006, en su art. 2º, fijó una meta de superávit estructural anual equivalente al 1\% del PIB anual, con la finalidad de conseguir una dinámica de acumulación de activos que permitiera hacer frente a compromisos futuros del sector público, advirtiéndose que de tales deberes y pasivos contingentes, los más significativos resultaban las garantías por pensiones mínimas y asistenciales, la situación patrimonial del Banco Central25, y la existencia de vulnerabilidades externas asociadas a descalces cambiarios.

\footnotetext{
24 Ante la crítica formulada por un diputado en orden de que esta norma no supondría un gran aporte, atendido que el Ejecutivo puede dictar otro decreto que modifique la posición ante la regla fiscal, el entonces Director de Presupuestos, señaló "la norma en comento busca que se explicite la política fiscal que se seguirá por un gobierno, lo que podrá determinarse con entera libertad. Sostuvo que el Gobierno ha venido implementando la regla del superávit estructural; no obstante, lo cual, al no constar en una norma jurídica, los analistas internacionales no la consideran como una "regla" propiamente tal. Es en razón de ello que se busca que en el futuro de haga constar la política fiscal en un instrumento normativo" (BCN, 2006, p. 22).

25 La razón de esa capitalización obedece a que con motivo del rescate financiero que efectuó el Banco Central en 1982, al discutirse el proyecto de ley de la especie, esa institución arrastraba el patrimonio negativo más voluminoso de los países emergentes y desarrollados. BCN (2006) p. 91.

La facultad de efectuar los aportes antedichos rigió por 5 años, y ella se practicó los años 2006, 2007 y 2008, por US\$ 606 millones, US\$ 736 millones, y US\$ 730 millones, respectivamente.
} 
De ahí que la citada meta de superávit se entendiera como un respaldo, dirigido a reducir el peso de la deuda pública, para minorar la exposición del tesoro a una serie de riesgos y acumular activos o capacidad de endeudamiento para evitar limitaciones de liquidez ${ }^{26}$.

Ahora bien, según se expresa en el Estado de Hacienda Pública 2009²7, tal objetivo de superávit se mantuvo solo hasta el año 2007, puesto que el 2008 aquel se redujo al 0,5\% del PIB ${ }^{28}$.

Más adelante, ya en medio de la crisis financiera, dicho $0,5 \%$ de objetivo pasó a un 0\% del PIB en 2009, no obstante lo cual, el déficit estructural de ese año alcanzó, según afirman algunos estudios, el 1,2\% ${ }^{29}$.

Conviene advertir que ninguna de esas alteraciones al decreto en cuestión, se implementó a través de un decreto modificatorio, lo que denota una falencia grave.

Por su parte, el decreto No 637, de 2010 se promulgó en un contexto de desarrollo de la citada crisis y con los estragos que provocó en el país el terremoto de febrero de esa anualidad, que implicó pérdidas estimadas por US\$ 29.700 millones (un 14,9\% del PIB) ${ }^{30}$.

Dado ese escenario, la postura que manifestó el gobierno entrante -plasmada en el art. $2^{\circ}$ original del anotado acto administrativo- fue del siguiente tenor: "La situación de déficit estructural que enfrenta esta Administración como punto de partida, sumada a la necesidad de implementar el Plan de Reconstrucción diseñado como respuesta al terremoto del 27 de febrero de 2010, así como la aplicación del Programa de Gobierno, justifican implementar una política fiscal que procurará converger a un balance estructural equilibrado hacia fines del actual período presidencial".

Ese año 2010, el déficit estructural se elevó al 1,6\% $\%^{31}$, y en tales circunstancias, a fines de septiembre de 2011, ante las dificultades de alcanzar el equilibrio al terminar el mandato presidencial, mediante el decreto No 1.357, de 2011, del Ministerio de Hacienda, se alteró el "compromiso" asumido, indicando que se esperaba "converger a un déficit estructural del $1 \%$ del producto interno bruto" hacia fines de ese gobierno.

A su turno, en 2014, al iniciarse el segundo mandato de la Presidenta Bachelet, se dictó el decreto No 892, que hizo presente el déficit estructural dejado por la administración anterior, indicando que su gobierno se fijaba como meta converger gradualmente a una situación de balance estructural para el año 2018.

\footnotetext{
26 Marcel (2013) p. 9.

27 Velasco (2009) p. 108.

28 Véase EngEL et al. (2007) pp. 1-15.

Se afirmó que la justificación a esa medida tenía base en que la deuda del Banco Central ya había sido saldada en buena parte, se había producido una disminución de los riesgos cambiarios, y el FRP permitía hacer frente a una cantidad significativa de pasivos contingentes relacionados con la seguridad social, entre otros aspectos, por lo que se estimó que resultaba el momento adecuado para un presupuesto estructuralmente equilibrado MARCEL (2013) p. 10; Frankel (2011) p. 42; Ffrench-Davis (2016) p. 157.

29 MarCel (2013) p. 18. Es menester, advertir que otros estudios indican que el déficit ese año se elevó al 3,1\% del PIB. Larraín (2010) p. 25.

30 Larraín (2010) p. 23.

31 Marcel (2013) p. 18.
} 
Sin embargo, tal como había ocurrido con la administración precedente, al año de vigor de esa norma, el Ejecutivo reconsideró, y, por ende, alteró el "compromiso" asumido, dictando el decreto No 1.378, de octubre de 2015, del Ministerio de Hacienda, que ahora contemplaba que la meta fiscal era, a partir del año 2016 y hasta 2018, reducir el déficit estructural en aproximadamente un $1 / 4 \%$ del PIB cada año.

Como se aprecia, si bien se establece un deber de fijar una posición, en ninguno de los tres períodos presidenciales de aplicación, los compromisos originales asumidos han podido ser cumplidos, y el Ejecutivo ha debido enmendar lo dicho, ajustando las proyecciones, sin que respecto a ello, exista fiscalización ni menos sanción alguna.

Lo anterior nos lleva a compartir lo dicho por Berganza ${ }^{32}$, en orden a que el cumplimiento de los objetivos de equilibrio estructural, en Chile, no es un asunto, en lo sustantivo, jurídicamente vinculante, atendido que no existen mayores límites para cambiar ello. Tampoco se prevé un procedimiento reglado para practicar esa modificación, la normativa no fija la trayectoria de retorno cuando se configuran desviaciones respecto al objetivo ni se contemplan sanciones o desincentivos concretos para que se practiquen tales alteraciones.

\section{FONDOS SOBERANOS CREADOS}

Como se adelantó, la ley No 20.128 creó el FRP y el FEES, los cuales permitieron una acumulación de activos ${ }^{33}$, que, en promedio, en el lapso 2006-2009, alcanzaron el $11,9 \%$ del PIB, los cuales -en razón de la paralela disminución de la deuda-generaron, en ese lapso, una posición acreedora neta, equivalente en promedio a $6,6 \%$, lo cual contrasta con la posición deudora neta del período 1990-2005, que promedió en un 15,8\% del PIB ${ }^{34}$.

De acuerdo con el último Informe Anual disponible en la página web del Ministerio de Hacienda, a fines de $2016^{35}$, dentro de los activos financieros del Tesoro Público, US\$9.079 millones correspondían al FRP y US\$14.698 millones al FEES.

Debe tenerse en cuenta que la gestión de activos financieros por parte del Fisco requiere de resguardos especiales, a través de una institucionalidad adecuada, procurando que tales precauciones no terminen conduciendo a inversiones especialmente conservadoras, y en consecuencia ineficientes ${ }^{36}$.

Cabe señalar que, a nivel internacional, se han alcanzado orientaciones y prácticas relativas a la inversión de los recursos estatales de esta clase, que se recopilaron, el año 2008, en lo que se denominan los Principios de Santiago, fruto del Grupo Internacional de Trabajo sobre Fondos Soberanos de Inversión del FMI ${ }^{37}$.

32 Berganza (2012) pp. 20-21.

33 Debe tenerse presente que el decreto No 1.492, de 2014, del Ministerio de Hacienda, reglamenta la coordinación y funcionamiento de las actividades de asesoría, apoyo a la gestión y fiscalización de los activos y pasivos financieros del Tesoro Público, en especial del FEES y el FRP.

34 Velasco et al. (2010) pp. 10-11.

35 Dirección de Presupuestos (2016) p. 24.

36 Marcel y Vega (2010) pp. 2-3.

37 SAfFirio (2012) pp. 572-575. 
Relacionado ello, debe decirse que inicialmente la política de asignación que se tenía con los recursos del FRP se basaba fundamentalmente en la experiencia del Banco Central en la administración de sus reservas internacionales, lo que cambió a partir del año 2011, en que se estableció una nueva política, orientada a que sus recursos se inviertan a horizonte de mediano a largo plazo, colocando estos caudales en instrumentos más riesgosos, como acciones y bonos corporativos extranjeros. Otro tanto ocurre con el FEES, según lo establecido en el Ord. No 1.567, de 2015, del Ministerio de Hacienda, que también admite la inversión en esa clase de valores mobiliarios.

Así las cosas, creemos pertinente la advertencia de Saffirio ${ }^{38}$, en orden que la incorporación de acciones y bonos corporativos entre los instrumentos en los cuales se invierten los recursos supone interesantes retos desde el punto de vista regulatorio, dado que debe prestarse atención a la identidad y objeto de las compañías emisoras, a fin de asegurar que, a través de sus inversiones, el Estado chileno no incumpla sus obligaciones internacionales en derechos humanos, medio ambiente y otros asuntos.

\subsection{Fondo de Reserva de Pensiones (Frp)}

Es aquel destinado, de acuerdo con el art. $5^{\circ}$ de la ley No 20.128, a complementar el financiamiento de obligaciones fiscales derivadas de la pensión básica solidaria de vejez, la pensión básica solidaria de invalidez, el aporte previsional solidario de vejez y el aporte previsional solidario de invalidez. Así, este Fondo busca transferir recursos entre generaciones, aminorando el impacto que provocarán los diversos compromisos asumidos por el Estado, que quedan dentro su ámbito ${ }^{39}$.

De acuerdo con el art. $6^{\circ}$ de la ley No 20.128 este Fondo ${ }^{40}$ se constituye e incrementa con los siguientes aportes:

a) Con un aporte equivalente al superávit efectivo con un tope del $0,5 \%$ del PIB del año anterior.

Ahora bien, si el monto resultante del aporte anual recién señalado fuese inferior al $0,2 \%$ del PIB del año anterior, debe enterarse como aporte este último porcentaje correspondiente al año anterior, independiente a que haya habido o no superávit efectivo.

b) Con el producto de la rentabilidad que genere la inversión de los recursos del FRP, y

c) Con los demás aportes que establezca la ley.

Por otro lado, el art. $7^{\circ}$ previene que los recursos solo pueden ser utilizados una vez transcurridos diez años desde la fecha de entrada en vigencia de la ley, lo que se verificó el 30 de septiembre de 2016, por lo cual, las sumas así acumuladas ya se encuentran en condiciones de ser utilizadas para los fines del art. $5^{\circ}$ antedicho, y en efecto, en 2017 , se realizaron retiros por 313,95 millones de dólares.

\footnotetext{
38 SAFFirio (2012) pp. 582-583.

39 Marcel y Vega (2008) p. 3.

40 El valor de mercado del FRP totalizó US\$10.123,76 millones a fines de mayo de 2017. MinISTERIO DE HACIENDA (2018a) p. 2.
} 
A su turno, el art. $9^{\circ}$ de la misma preceptiva prevé que el FRP debe mantenerse en una o más cuentas especiales del Servicio de Tesorerías, y sus recursos pueden invertirse en instrumentos, realizar operaciones y celebrar los contratos que señala el inciso segundo del art. 45 del decreto ley $\mathrm{N}^{\circ} 3.500$, de $1980^{41}$, tanto en Chile como en el extranjero, sin que las inversiones puedan efectuarse en acciones ${ }^{42}$ de sociedades anónimas abiertas (limitación que debe entenderse solo a las compañías chilenas, atendido que el No 10 del art. $1^{\circ}$ del reglamento de la materia, expresamente permite la inversión en "acciones y bonos emitidos por empresas extranjeras"), conforme a las normas, límites, procedimientos y controles que fijados, en la especie, en el decreto No 1.247, de 2017, del Ministerio de Hacienda.

Agrega más adelante, que, para los antedichos efectos, la Tesorería General de la República debe contratar servicios de administración de carteras de inversión de los recursos del FRP mediante licitación pública, cuyos prestadores e intervinientes quedan afectos a las responsabilidades civiles, penales y administrativas, por los perjuicios, delitos o infracciones cometidas en la contratación y administración de tales servicios.

\subsection{Fondo de Estabilización Económica y Social (feEs)}

Su objetivo es otorgar estabilidad financiera al Fisco, permitiendo ahorrar parte de los superávits fiscales ${ }^{43}$, que luego pueden convertirse en mayor gasto, que sustente el presupuesto en años de baja del ciclo económico.

La normativa de este fondo soberano figura en el decreto con fuerza de ley $\mathrm{N}^{\circ} 1$, de 2006, del Ministerio de Hacienda, en mandato de lo previsto en el art. 10 de la ley No 20.128, que facultó al Presidente de la República para que refunda en el FEES los recursos de estabilización de los ingresos fiscales del decreto ley $\mathrm{N}^{\circ} 3.653$, de 1981 y los del Fondo de Compensación para los Ingresos del Cobre ${ }^{44}$, constituido conforme al Convenio de Préstamo BIRF No $2625 \mathrm{CH}$, en 1985.

\footnotetext{
41 Que singulariza los destinos susceptibles para ser invertidos por parte de las AFP. Entre otros instrumentos que se especifican, figuran títulos emitidos por el Banco Central de Chile; bonos emitidos en Chile por instituciones financieras chilenas; bonos de empresas privadas chilenas, salvo bonos canjeables por acciones; cuotas de fondos de inversión y mutuos; acciones y bonos emitidos por empresas extranjeras; cuotas de participación emitidas por fondos mutuos y fondos de inversión extranjeros.

42 La justificación de que se excluya a estos instrumentos de renta variable como susceptible de inversión por parte de los recursos acumulados por el FRP, obedece a que se busca evitar una discusión de lo que significaría que el Tesoro Público y en consiguiente actúe como empresario, atendido lo dispuesto por inciso segundo del art. 19, No 21 de la Constitución. BCN (2006) pp. 113-114, 179-184.

43 El valor de mercado del FEES fue de US\$14.937,57 millones a fines de marzo de 2018, totalizando aportes por US\$21.765,71 millones, y retiros por US\$10.852,81 (la diferencia respecto a la cifra final se debe a los incrementos por conceptos de intereses devengados, ganancias y pérdidas de capital y costos de administración). MiNISTERIO DE HaCIENDa (2018b) p. 2.

44 Ese fondo entró a operar en 1987, y se concibió bajo la lógica de ahorrar los recursos adicionales que se perciban cuando el precio del cobre esté por sobre su precio de largo plazo, permitiendo inyectar los recursos acumulados cuando se encuentre bajo ese monto. En los años de bonanza esos recursos congregados se utilizaron para solventar la deuda externa. Véase Arellano (2006) pp. 179-180, 183-185; Marcel y Vega (2008) p. 7.
} 
El anotado decreto con fuerza de ley (al cual se hará alusión en este acápite) prevé, en su art. $2^{\circ}$, que el FEES se constituye e incrementa con los recursos que señala ${ }^{45}$.

A su turno, el art. $4^{\circ}$ se encarga de detallar los destinos que puede tener los recursos del fondo en cuestión, indicando que estos pueden ir:

a) al financiamiento de la Ley de Presupuestos, hasta por el monto que se establezca en dicha ley, y que se incluya en el Cálculo de Ingresos Generales de la Nación respectiva;

b) a la sustitución de ingresos y/o financiamiento de mayor gasto que se produzca durante la ejecución presupuestaria, conforme a las autorizaciones y limitaciones establecidas en la legislación vigente;

c) a las amortizaciones, intereses u otros gastos por concepto de Deuda Pública, incluidos los originados en contratos de canje de tasas de interés y/o de monedas;

d) a las amortizaciones, intereses u otros gastos por concepto del pago de Bonos de Reconocimiento a que se refiere el art. 11 transitorio del decreto ley $\mathrm{N}^{\circ} 3.500$ de 1980, incluidos los originados en contratos de canje de tasas de interés y/o de monedas;

e) al financiamiento del aporte a que se refiere la letra a) del art. $6^{\circ}$ de la ley $\mathrm{N}^{\circ}$ 20.128 (aporte mínimo al FRP), cuando así lo disponga el Ministro de Hacienda; y

f) al financiamiento de aportes extraordinarios al FRP, cuando así lo disponga el Ministro de Hacienda.

En tanto, el art. $5^{\circ}$ señala que los recursos del Fondo pueden invertirse en instrumentos, operaciones y contratos que establezca el Ministro de Hacienda mediante instrucciones $^{46}$.

Más adelante, el art. $6^{\circ}$ previene que, para la administración e inversión de los recursos del Fondo, el Ministro de Hacienda puede contar con instancias administrativas de asesoría y de apoyo a la gestión, las que deben estar constituidas por personal de dicha Secretaría de Estado y de sus servicios dependientes, que sean designados para tal efecto. Para tales fines, se consigna que un reglamento debe establecer las normas de integración, actividades o funciones, coordinación y funcionamiento de las instancias antes señaladas, así como las demás normas necesarias para el funcionamiento, supervisión y control del Fondo.

Expuestas las normas mencionadas nos parece oportuno hacer presente que a nuestro entender la regulación anotada no determina con certeza cuándo procede el empleo de los recursos acumulados en el FEES, atendido que varios literales del art. $4^{\circ}$ del decreto con fuerza de ley citado entregan a la discrecionalidad del Ejecutivo estos desembolsos, sin prever tampoco la magnitud específica de esos giros, siendo a nuestro juicio, un punto que requiere de un análisis crítico ${ }^{47}$.

\footnotetext{
45 El FEES se alimenta con incrementos anuales del superávit efectivo del año anterior, si lo hubiere, restándole a eso el monto del aporte que se realiza al FRP. Así, el aporte oscilará entre un $0,5 \%$ y un $0,8 \%$ del PIB, dependiendo de lo que se haya decidido aportar al primer fondo y primeramente, de que efectivamente se haya verificado superávit.

46 Véase Ord. No 1.567, de 2015, del Ministerio de Hacienda.

47 Marcel y Vega (2008) p. 17.
} 
Ello difiere de lo que ocurre en otros países ${ }^{48}$, en que se ha precisado de manera previa, los supuestos que habilitan al Gobierno para hacer uso de las políticas anticíclicas (empleando recursos como los que se acumulan en un fondo del tipo del FEES).

\subsection{EMPleo de los ReCURSOS ACUMUlados DuRANTE la CRISIS DEL AÑo 2008}

Como se ha mencionado, el año 2008, ante la crisis económica internacional que implicaba el mayor shock externo en 50 años ${ }^{49}$, el Gobierno aceleró el desembolso de recursos, con un alza del gasto fiscal de 2\% del PIB, no obstante la caída de 9,5\% de sus ingresos.

Luego, en 2009, elevó ese gasto en 3\%, a pesar de la caída adicional del 20,4\% de sus entradas, teniendo en cuenta que el precio de la libra de cobre que, a comienzos de 2008 se cotizaba a US\$ 4,00, a final del año había descendido a US\$ 1,4 .

En efecto, utilizando esta herramienta, el año 2009, se implementó un plan de estímulo -mediante una política fiscal más expansiva que la permitida por la regla ${ }^{50}$, que llevó a modificar la metodología pertinente de cálculo- para dinamizar la economía y la generación de empleo ${ }^{51}$, que consideró medidas por US\$4.000 millones, equivalentes a 2,8\% del PIB, lo que al momento de su anuncio lo ubicó como el quinto más grande a nivel mundial en términos de porcentaje del PIB $^{52}$ y el más importante de la región ${ }^{53}$.

En este contexto, se adoptaron diferentes decisiones que significaron que la suma total de recursos retirados del FEES, durante 2009, ascendió a US\$9.277 millones ${ }^{54}$, sin la necesidad de acudir al financiamiento internacional.

\section{ASPECTOS ORGÁNICOS EN EL FUNCIONAMIENTO DE LA REGLA FISCAL}

En Chile, el Ministerio de Hacienda es el encargado de conducir, de modo general, las finanzas públicas, y en tal contexto también la regla fiscal, no obstante lo cual se han creado entidades especializadas, bajo su dependencia, que le prestan labores de apoyo ${ }^{55}$.

\subsection{Comité Financiero}

Organismo al cual hace referencia el art. 13 de la ley No 20.128, que es regulado en el decreto No 621, de 2007, del Ministerio Hacienda, que tiene como función principal,

\footnotetext{
48 Como Colombia (art. 6 de la ley No 1.473, de 2011), Perú (art. 5 de la ley No 27.245, de 1999, entre otros. Véase GaLÁN (2014) pp. 62-63.

49 MarCel (2013) p. 23.

50 Comité Asesor (2011) p. 40; Marcel (2013) p. 18.

51 Véase ACEVEDo et al. (2014) pp. 50-54.

52 Velasco (2010) p. 102.

53 Marcel (2013) p. 25.

54 LaRraín (2010) p. 24.

55 En la especie, mediante el decreto No 1.383, de 2006, del Ministerio de Hacienda, se delegó la representación del Fisco para la inversión de los recursos correspondiente a los Fondos mencionados en el Banco Central de Chile.
} 
de acuerdo con su art. 10, "asesorar" "56 a esa Secretaría de Estado en materia de inversión de los recursos fiscales de los fondos soberanos ya mencionados.

Este cuerpo colegiado está integrado por 6 profesionales ${ }^{57}$, destacados en el área de la economía, con experiencia en la administración de carteras de inversión, que hayan ejercido el cargo de gerente o ejecutivo principal en alguna empresa del sector financiero, incluyendo las empresas públicas, el Banco Central y organismos financieros internacionales, o se desempeñen o se hayan desempeñado como académicos en alguna universidad o centro de estudios superiores.

Los miembros quedan sujetos a diversas obligaciones, entre las que se cuentan no usar información privilegiada en sus recomendaciones, guardar reserva y abstenerse de usar para beneficio propio la información a la que tengan acceso con motivo de su cargo, y abstenerse de debatir y votar temas en los que tengan interés. El incumplimiento de cualquiera de ellas implica la cesación inmediata del cargo y hace exigibles las responsabilidades civiles o penales que de él se sigan, además de las sanciones administrativas pertinentes.

A su turno, es necesario señalar que mediante el decreto No 1.251, de 2014, del Ministerio de Hacienda, el aludido decreto No 621 fue modificado agregándosele a la preceptiva que fijaba la sanción de remoción por incumplimiento de los deberes antedichos la frase, "sin perjuicio de lo anterior cualquier integrante del Comité cesará en el cargo por disposición del Ministro de Hacienda manifestada mediante resolución”, luego de un conflicto que se suscitó entre esa Cartera y un miembro de ese cuerpo asesor ${ }^{58}$ que manifestó públicamente discrepancia con algunas ideas de inversión comunicadas por el Ejecutivo, lo que evidencia la escasa autonomía de este órgano colegiado en el ejercicio de sus funciones.

En razón de lo dicho, no se cumple con el carácter de "independiente" 59 que debiese tener este tipo de entidades, y de ahí que compartamos la propuesta de que, dentro de la institucionalidad de la regla fiscal chilena, este es un tema que se "requiere fortalecer" ${ }^{\circ}$.

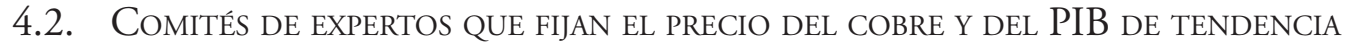

El cálculo de estos elementos que resultan centrales para la ejecución de la regla fiscal se efectúa por comités de expertos "independientes" -que fueron creados los años 2001 y 2002 , respectivamente ${ }^{61}$, esto es, antes de la entrada en vigor de la ley No 20.128-, lo cual brindaría credibilidad a la ejecución del sistema.

\footnotetext{
56 Dado el tenor de la normativa chilena no compartimos lo dicho por Berganza. Berganza (2012) p. 21, en cuanto a que este comité "supervisa" (supervises) el funcionamiento de los fondos soberanos, pues, este cuerpo es meramente asesor, y la supervisión en sí, importa "ejercer la inspección superior en trabajos realizados por otros" RAE (2017), facultades que le son ajenas.

57 Los integrantes del Comité Financiero duran 2 años en sus cargos, pudiendo ser designados por nuevos períodos.

58 El conflicto tuvo como protagonistas al en ese momento miembro del comité, señor Arturo Cifuentes y las autoridades del Ministerio de Hacienda de aquel entonces.

59 Parrado et al. (2012) p. 97.

60 PARRAdo et al. (2012) p. 115.

${ }^{61}$ Ffrench-Davis (2016) p. 154; Comité Asesor (2011) p. 37.
} 
Debe recordarse que el citado art. 10 del decreto ley No 1.263, de 1975, ordena al Ministerio de Hacienda a dictar un decreto que establezca la metodología de cálculo y la forma de recabar la información para su aplicación.

Es interesante advertir que desde el mundo de la economía, variados estudios expresan que el hecho de que el cálculo de estos factores quede entregado a estos cuerpos "independientes" le conferiría transparencia al funcionamiento del sistema ${ }^{62}$, pasando por alto el cuestionarse si dada la configuración de estos organismos, su modo de nombramiento y funcionamiento, aquella independencia es efectiva, atendida la circunstancia que la designación de sus miembros queda entregada a una simple resolución del Ministerio de Hacienda, la cual, ni siquiera cuenta con un control preventivo de juridicidad, como ocurriría si su estructura y funcionamiento estuviere normada, al menos, en un decreto supremo, con las prevenciones que, de todos modos formulamos cuando revisamos el Comité Financiero.

Por lo demás, estimamos necesario hacer presente que no obstante el tenor de la normativa legal acerca de la necesidad de la configuración de este comité de expertos independientes, a más de 10 años de la aprobación de la ley No 20.128, aún no se ha dictado el decreto que norme a esas entidades. Ahora bien, somos de la idea que la autonomía de las instituciones que proveen los elementos técnicos sobre los cuales se construye la aplicación de la regla debiesen consignarse en una normativa de rango legal, a fin de evitar su modificación a la simple discrecionalidad del Ejecutivo, teniendo en cuenta el precedente del Comité Financiero. En efecto, el profesor de la Universidad de Harvard Jeffrey Frankel acota que "un refuerzo útil de la idea de Chile sería formalizar los detalles del procedimiento en una ley y otorgar a los paneles independencia legal. Podría existir una ley que los protegiera contra el despido, como ocurre con las autoridades de los bancos centrales autónomos" 63 .

A su turno, la misma carencia de una norma positiva estable, se da en relación con la metodología de cálculo de la regla, respecto de lo cual ex autoridades en estas materias se bastan con afirmar que "la metodología de cálculo original como sus perfeccionamientos han sido publicados por la Dirección de Presupuestos del Ministerio de Hacienda" ${ }^{64}$ omitiendo que ello no se ha hecho a través del medio formal que exige el legislador. En efecto cabe hacer presente que ya el Informe de la Comisión Corbo, del año 2011, exhortaba al Gobierno, para que publique "en no más de un año el reglamento para el cálculo del BCA (Balance Cíclicamente Ajustado), tal como lo indica la Ley sobre Responsabilidad Fiscal”, comunicando "públicamente todo cambio metodológico al cálculo del BCA, previo a su aplicación". Requiriendo también "la publicación de las actas de los comités consultivos del precio del cobre y del PIB tendencial, definiendo fechas de las convocatorias y plazos para la publicación de las actas" ${ }^{65}$ a fin de darle mayor transparencia en su actuar.

\footnotetext{
62 Guzmán y Marcel (2008) p. 307; Acevedo et al. (2014) pp. 26-27; Frankel (2011) p. 44; Ardanaz et al. (2015) p. 29; García (2012) pp. 25, 33; Marcel (2013) pp. 12, 33; Budina et al. (2012) p. 17; Ter-Minassian (2011) p. 135.

63 Frankel (2011) p. 65.

64 Velasco et al. (2010) p. 6.

65 Comité Asesor (2011) pp. 100-101.
} 
En la práctica, la metodología antedicha se presenta a través de un documento denominado Indicador del Balance Cíclicamente Ajustado ${ }^{66}$, que, en tal condición, no se ajusta a lo ordenado por la normativa de que se trata.

Ahora bien, no podemos dejar de mencionar que, en mayo de 2018, se ha sometido un proceso de consulta pública, mediante la página web de la Dirección de Presupuestos, de un proyecto de decreto que pretende regular la metodología de cálculo, procedimiento y publicación del balance estructural, instrumento que por encontrarse en fase preliminar no puede ser analizado. En razón de lo anterior, no podemos sino disentir con Berganza ${ }^{67}$, cuando afirma que en Chile se cuenta con un cuerpo independiente que establece los supuestos presupuestarios y metodologías atingentes (como el cálculo del PIB tendencial y los precios de referencia del cobre), elementos claves para la implementación de la regla, atendido que tales comités carecen de autonomía, de acuerdo con los argumentos expuestos.

\subsection{Consejo Fiscal Asesor (CFA)}

Entidad creada a través del decreto No 545, de 2013, del Ministerio de Hacienda, a fin de fortalecer la institucionalidad que sostiene el sistema de responsabilidad fiscal, siguiendo las sugerencias formuladas por el Informe Corbo (al cual se hará referencia más adelante).

El CFA, según el art. $1^{\circ}$ del aludido decreto, es un órgano cuyo objeto es "colaborar en la discusión, análisis y emisión de recomendaciones en materias relacionadas con la determinación del balance estructural”.

La creación de este consejo responde a una búsqueda de una mayor transparencia en el proceso de determinación del balance estructural.

El CFA se conforma por 5 miembros, expertos en temas fiscales y presupuestarios. Su nombramiento está a cargo del Ministro de Hacienda, quien designa a los integrantes, por un periodo de 4 años.

El Consejo debe realizar las actividades específicas que indica el art. $2^{\circ}$ del mencionado decreto, en reuniones que deben celebrarse al menos una vez por semestre, previa citación del Secretario de Estado referido, y cada vez que este lo convoque. Entre aquellas labores cabe destacar la participación de sus miembros como observadores en los Comités de PIB Tendencial y de Precio de Referencia del Cobre, y también la de efectuar un pronunciamiento respecto del cálculo del ajuste cíclico del balance estructural realizado por la Dirección de Presupuestos.

Ahora bien, a nuestro juicio, si se contase con una institucionalidad adecuada, y uno o más organismos efectivamente autónomos, que se encarguen de proveer la información necesaria para la aplicación de la regla, hacer propuestas de inversión de los recursos captados para los fondos soberanos y evalúe(n) con carácter general el funcionamiento del sistema, la existencia de una entidad de esta clase parece redundante o innecesaria, teniendo en cuenta que, por lo demás, también sus miembros son designados unilateralmente por el Ejecutivo.

\footnotetext{
66 ACEvedo et al. (2014) p. 30

67 Berganza (2012) p. 36.
} 


\section{EVALUACIÓN DEL FUNCIONAMIENTO DEL SISTEMA POR EL COMITÉ ASESOR}

En mayo de 2010 se convocó un Comité Asesor integrado por destacados expertos, presididos por Vittorio Corbo, a quienes se les encomendó diseñar propuestas para perfeccionar el sistema de cálculo del balance estructural, de forma tal que los resultados que se obtuviesen demostraren una aproximación más certera para una política fiscal sustentable y predecible, fortaleciendo la transparencia y la rendición de cuentas por parte de la autori$\mathrm{dad}^{68}$, ya que la credibilidad en su cumplimiento ${ }^{69}$, se vio mermada luego de los cambios de objetivo del superávit del $1 \%{ }^{70}$, a los cuales ya se hizo referencia.

El trabajo de ese grupo se plasmó en el documento denominado "Propuestas para perfeccionar la Regla Fiscal; informe final del Comité Asesor para el diseño de una política fiscal de Balance Estructural de segunda generación para Chile”, más conocido como "Informe Corbo", que contiene ideas y propuestas para perfeccionar el sistema en su conjunto, centrándose esencialmente en sugerencias de corte metodológico para simplificar las fórmulas de cálculo correspondiente (que fueron sucesivamente alteradas ${ }^{71}$ ), a fin de que el balance cíclicamente estructurado se ajuste a las circunstancias económicas del país.

Ahora bien, atendido carácter técnico económico de esas propuestas, ellas no son objeto de análisis en este informe, el cual, se ciñe a los asuntos de naturaleza jurídica normativa.

Luego, desde un punto de vista funcional una de sus recomendaciones es la inserción de causales que permitan al Gobierno apartarse de la meta que se fijó, si concurre un hecho excepcional que le haga imposible mantener esa posición sin un grave detrimento a la economía del país, acompañadas de la definición de medidas, que establezcan cómo recuperar la trayectoria de la política fiscal una vez superada la situación extraordinaria ${ }^{72}$.

A fin de que no se abuse en el empleo de estas cláusulas de escape, otros autores han propuesto que para que su procedencia sea admisible, debiese justificarse mediante informes emitidos por organismos independientes que respalden la necesidad de adoptar ese camino, como también que su aprobación quede sometida a la venia del Congreso Nacional, procurando se retorne al cumplimiento previsto en un plazo no mayor a 2 años $^{73}$.

Se presentaron una serie de propuestas a fin de hacer más transparente el funcionamiento del sistema, asegurando una rendición de cuentas de lo hecho sobre el particular, para sí brindar coherencia intertemporal a la política fiscal de Chile.

Además, se incluyó un apartado sobre la institucionalidad, que, basándose en la experiencia comparada, recomendó la formación de un Consejo Fiscal Independiente, cuya función principal sea la revisión y evaluación del cumplimiento de las metas y objetivos del

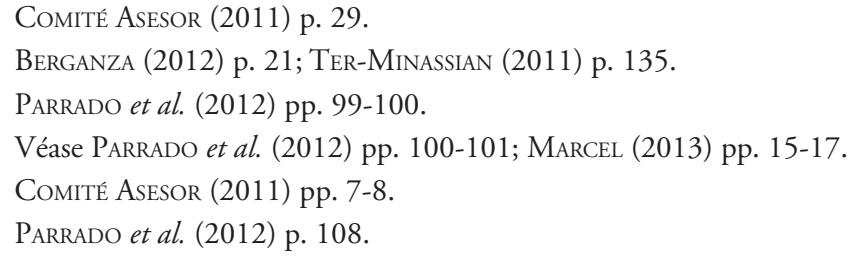


sistema de responsabilidad fiscal. Un organismo de esta clase puede "encargarse de evaluar si el presupuesto planteado por el gobierno alcanzará el objetivo presupuestario estructural deseado" 74

En particular, el informe sugiere ${ }^{75}$ que ese último cuerpo tenga carácter autónomo ${ }^{76}$, con miembros propuestos por el Presidente, ratificados por el Congreso, con una duración en su cargo diferente a la presidencial, y con funciones especificadas por el legislador, para que supervise y asesore a las entidades correspondientes sobre la regla de superávit fiscal y la liquidez del sector público.

Asimismo, se propone que evalúe la metodología de la regla fiscal adoptada por el Ejecutivo; presente, a fines de cada año, un informe anual sobre la política fiscal, la aplicación de la regla en análisis y la sostenibilidad de mediano y largo plazo de la política antedicha, cuantificando los riesgos emergentes, y evalúe y emita opinión, respecto de la pertinencia de la invocación de cláusulas de escape y la estrategia de convergencia a la meta del balance cíclicamente ajustado, en caso de activarse esta.

Haciendo eco de la referida propuesta la Administración del Presidente Piñera presentó un proyecto de ley que recogía, parcialmente, algunos de esos planteamientos, fechado el 4 de marzo de 2014, e ingresado a la Cámara de Diputados (por el Gobierno que le sucedió) en mayo de la misma anualidad, el que fue retirado el 3 de junio de ese mismo año.

Ahora bien, es menester consignar, en el referido proyecto de ley al organismo concebido se le mantenía el carácter meramente consultivo del Ministerio de Hacienda, contemplándose además que la designación de sus miembros quede entregada al Ejecutivo, sin intervención de otro poder del Estado, por lo que la autonomía no se concretaba.

\section{EFECTOS DE LA ADOPCIÓN DE LA REGLA FISCAL}

La regla fiscal en Chile colaboró en la reducción, en un tercio, de la volatilidad del crecimiento $^{77}$. En tal sentido, diversos estudios han sostenido que ello condujo a aumentar el ahorro público, permitiendo una significativa reducción de la deuda pública neta ${ }^{78}$. También sirvió para mejorar la credibilidad del Fisco chileno, reduciendo las percepciones de riesgo sobre la economía y mejorando el acceso al financiamiento externo.

Asimismo, ha dado pie para la adopción de políticas fiscales contracíclicas ya enun$\operatorname{ciadas}^{79}$, concitando el apoyo de amplios sectores ${ }^{80}$.

El positivo escenario que fueron construyendo las autoridades en los primeros años de aplicación de la regla fiscal, que podemos resumir en una disminución de la deuda, en la acumulación de ahorros atendido el superávit, y en el logro de una posición de acreedor

\footnotetext{
Frankel (2011) p. 66.

Comité Asesor (2011) pp. 94-100.

Berganza (2012) pp. 10, 22.

7 Larraín y Parro (2008) p. 563.

78 Ter-Minassian (2011) p. 136.

79 Parrado et al. (2012) p. 90.

80 Comité Asesor (2011) p. 25.
} 
neto, sirvieron para que el año 2010, el Gobierno acudiera a los mercados internacionales a emitir deuda, en condiciones muy favorables ${ }^{81}$, dado el bajo nivel de riesgo país. Sin embargo, atendidos los sucesivos presupuestos deficitarios y los reiterados incumplimientos a las pautas autoasumidas, han hecho cambiar ese escenario.

\section{ANÁLISIS ORGÁNICO Y FUNCIONAL DE LA REGLA CHILENA}

Como se ha visto, la institucionalidad y los aspectos funcionales, desde un punto de vista jurídico, son débiles, puesto que el grueso de las medidas queda entregada a la discrecionalidad del Ejecutivo, y son muy pocos los elementos que se encuentran previstos en la ley No 20.128, motivo por el cual, basta con la mera voluntad del Gobierno, para alterar, por ejemplo, la metodología de cálculo de la regla; incidir en los factores de tendencia que se cuantifican (cobre y PIB) -al designar los miembros de los comités pertinentes-; dirigir las instrucciones de inversión de los recursos de los fondos soberanos, pudiendo desatender los consejos de su comité asesor, y modificar la posición o compromiso en relación a la regla fiscal, entre otros, sin que exista otro Poder del Estado que pueda -efectivamente- desincentivar, ni menos reprochar o sancionar esos comportamientos unilaterales.

Durante un tiempo, la carencia de reglas positivas no fue cuestionada mayormente desde el Derecho en Chile, atendidos los logros alcanzados por la economía, que permitían que se generasen ahorros, y se pudieran mitigar satisfactoriamente las turbulencias internacionales.

Sin embargo, durante ya un largo lapso los resultados fiscales chilenos vienen arrastrando cifras deficitarias, por lo que se hace imperioso su análisis, a fin de poder sugerir los cambios necesarios, con el objeto de que la conducción hacendística vuelva a lograr grados de credibilidad, que atendidas las cifras que se exhiben hoy quedan puestos en duda.

No es rol puntual del abogado ponderar si es positivo o no que exista déficit o que la cifra que limite la deuda alcance tal o cual monto, su función es analizar las normas jurídicas que implementan la institución específica e indagar, con mirada crítica, si las reglas fijadas para tal fin resultan vinculantes ${ }^{82}$, y es por ello que, luego de haber revisado la historia de la ley No 20.128 y haber leído las bondades conceptuales que llevaría consigo la adopción de una regla fiscal que ayude con la estabilidad de las finanzas públicas, es que nos parece oportuno dar las señales de alerta, y proponer que se realicen las modificaciones regulatorias que aseguren la eficacia de las ideas perseguidas por el legislador al establecer esta herramienta de política fiscal dentro de nuestro ordenamiento.

\section{CONCLUSIONES}

Chile ostentó favorables números al comenzar a implementar su regla fiscal, sin embargo, el Informe de Finanzas Públicas de 2017 deja en evidencia que ese año se presenta un déficit efectivo de $2,7 \%$ del PIB y para el 2018 se espera un déficit de 1,9\% del PIB

81 ACEVEDO et al. (2014) pp. 46-48.

82 García y Martínez (2013) p. 25; Ruiz (2008) p. 75. 
proyectado. Lo que en términos estructurales arroja un déficit estimado para 2017 de 1,7\% del PIB y para el año 2018 este valor se espera en torno a 1,5\% del PIB estimado ${ }^{83}$.

La falta del establecimiento de la metodología de cálculo de la regla fiscal mediante una norma, que no sea discrecionalmente alterable, es una crítica que podemos formular, puesto que ello debilita la credibilidad al cumplimiento de los objetivos asumidos.

También creemos pertinente que se fijen criterios para la variación del gasto público, de conformidad con los parámetros que se estimen adecuados a la realidad del país, habida cuenta que medidas de ese tipo permiten dar mayor previsibilidad a los agentes económi$\cos ^{84}$, dejando márgenes de flexibilidad ante determinadas hipótesis.

Por otra parte, si bien la preceptiva vigente permite que se efectúen cambios en los objetivos planteados acerca de la regla fiscal durante el período presidencial respectivo, no se puede dejar de mencionar que ello no parece del todo conveniente. Al respecto, usualmente en el Derecho comparado ${ }^{85}$ ante circunstancias excepcionales se han contemplado válvulas de escape para supuestos tasados ${ }^{86}$, fijándose, a la par, una trayectoria para retomar los objetivos centrales ${ }^{87}$, figuras que son ajenas en la legislación chilena -cuyas autoridades han incurrido en "cláusulas de escape de facto" ${ }^{88}$-, y tal carencia, y predominio de la discrecionalidad afecta la confianza en la regla misma ${ }^{89}$.

En efecto, el Presidente del Banco Central ha afirmado que una cláusula de escape es una mejor alternativa que una suspensión o abandono de una regla fiscal, o una eliminación ex-post del compromiso para lograr la meta, atendido que de seguir estos caminos se produce un cuestionamiento a la noción misma de regla fiscal, erosionando su credibilidad y permitiendo que se abran espacios a la manipulación de la política fiscal ${ }^{90}$.

Además, debiesen contemplarse organismos fiscales efectivamente independientes, que, de modo autónomo al Gobierno de turno, evalúen y velen por el cumplimiento de las reglas que las propias autoridades asumen ${ }^{91}$.

Para limitar efectivamente la discrecionalidad ante ajustes estructurales de objetivos y cláusulas de escape, se requiere de una plataforma institucional para garantizar mayores niveles de consistencia. Con este fin, debiese crearse un Consejo Fiscal, legítimo en su origen, que garantice transparencia, ecuanimidad, independencia y coherencia en el seguimiento de la regla, de sus modificaciones y excepciones futuras ${ }^{92}$.

\footnotetext{
3 Dirección de Presupuestos (2017) p. 15.

84 Comité Asesor (2011) pp. 53-54.

85 Véanse, a modo de ejemplo, el art. 135.4 de la Constitución Española y el art. 109.3 de la Ley Fundamental de Alemania, entre otros.

86 Frankel (2011) p. 66; Comité Asesor (2011) pp. 41, 50-53.

87 Acevedo et al. (2014) p. 56.

88 Budina et al. (2012) p. 17

89 García (2012) pp. 21-22.

90 Marcel (2013) pp. 38-39.

91 Berganza (2012) p. 36.

92 Marcel (2013) pp. 46, 47.
} 
Hacemos la prevención, con todo, que un Consejo Fiscal, no debe tener a su cargo la conducción de la política fiscal misma, puesto que esa es una atribución del Poder Ejecutivo, pero sí debe ponderar, con autonomía, las pautas normativas vigentes al efecto.

Por otra parte, en Chile no queda claro quién debe conocer acerca del incumplimiento de las regulaciones de responsabilidad fiscal, materia que también debiese revisarse, a fin de disuadir la infracción de la preceptiva correspondiente.

Si bien, en su oportunidad, la regla del superávit estructural, antes de la aprobación de la ley No 20.128, fue elogiada porque aun cuando no estaba establecida en una norma positiva, el Ejecutivo dio cumplimiento al compromiso "tácito" acerca del debido uso de los recursos fiscales ${ }^{93}$, hoy con el paso de los años, apreciamos que la regulación vigente no resulta adecuada para asegurar el correcto funcionamiento de las finanzas públicas y, en razón de ello, es necesario dar un paso más allá para asegurar disciplina en la materia.

En efecto, Marcel dados los incumplimientos a la regla que se han producido, y ante las dificultades para su recuperación ha formulado un llamado para someter la norma fiscal a un escrutinio detallado, a fin de volver a legitimarla en un nuevo contexto político y económico, a objeto de ratificar sus principios básicos, fortalecer sus bases institucionales y recalibrar su metodología ${ }^{94}$.

En esta clase de diálogos, el Derecho no puede mantenerse al margen como lo ha estado en estos 17 años, y debe abrir caminos para el mejoramiento y la socialización de esta temática.

Atendido lo anterior, y también en base a la experiencia comparada, luego de que se efectúe ese proceso participativo, que pondere los distintos elementos involucrados, como es el sacrificio de intergeneracional de los ciudadanos de hoy, en favor de los de mañana; la evaluación de la conveniencia de inversiones con caudales públicos en compañías extranjeras, y otros aspectos de esa índole, creo que estaríamos en condiciones de considerar la pertinencia de incorporar en nuestra Constitución, como norma de mayor jerarquía dentro del ordenamiento jurídico patrio, una regla fiscal que configure las líneas centrales de las finanzas públicas.

Hacemos la salvedad, en todo caso, que se estima que las restricciones presupuestarias a las cuales usualmente quedan sujetas las autoridades en cumplimiento de pautas de este tipo, en ningún caso pueden importar un menoscabo en las prestaciones de los derechos esenciales, que son inherentes al Estado Social y Democrático de Derecho ${ }^{95}$, que constituye una finalidad y objetivo en sí mismo. Motivo por el cual, creemos que estos límites son un llamado para que exista un uso eficiente de los recursos públicos, con los adecuados controles, para evitar asignaciones innecesarias y malversación de los caudales, y también dar prioridad a determinadas prestaciones, como las vinculadas en temas sociales, frente a otros gastos como aquellos vinculados con defensa, protocolo y, en general, gastos superfluos, que bien pueden reducirse, sin menoscabar la dignidad de la persona humana, cuya protección y cuidado es deber inherente del Estado.

93 Arellano (2006) pp. 181-182.

94 Marcel (2013) p. 42.

95 Faggiani (2016) pp. 759-762. 


\section{BIBLIOGRAFÍA CITADA}

Acevedo, Maximiliano, Chamorro, Jessica, Roeschmann, Juan y Vega, Alejandra (2014): "Regla de Política Fiscal en Chile: Balance Cíclicamente Ajustado. Avances y desafíos", Revista Internacional de Presupuesto Público, No 86: pp. 11-58.

Ardanaz, Martín, Corbacho, Ana, Gonzales, Alberto y Tolsa, Nuria (2015): "Equilibrios fiscales estructurales en América Latina y el Caribe. Nuevo conjunto de datos y estimaciones", Revista Internacional de Presupuesto Público, No 89: pp. 11-44.

Arellano, Juan Pablo (2006): "Del déficit al superávit fiscal: razones para una transformación estructural en Chile”, Estudios Públicos No 101: pp. 165-186.

Berganza, Juan Carlos (2012): "Fiscal rules in Latin America: a survey" Disponible en: $<$ http://www.bde.es/f/webbde/SES/Secciones/Publicaciones/PublicacionesSeriadas/DocumentosOcaDocument/12/Fich/do1208e.pdf >

BCN-Biblioteca del Congreso Nacional (2006): "Historia de la ley No 20.128” Disponible en: <http://www.bcn.cl/historiadelaley/fileadmin/file_ley/5507/HLD_5507_37a6 259cc0c1dae299a7866489dff0bd.pdf>

Budina, Nina, Kinda, Tidiane, Schaechter, Andrea y Weber, Anke (2012) "Fiscal Rules at a Glance: Country Details from a New Dataset", International Monetary Fund-Working Paper No 273: pp. 1-61.

CeA, José Luis (2013): Derecho Constitucional Chileno, tomo 3 (Santiago, Ediciones. Universidad Católica de Chile, tercera edición).

Comité Asesor para el diseño de una política fiscal de balance estructural de SegunDA Generación para Chile (2011) "Propuestas para perfeccionar la regla fiscal" Disponible en: <http://www.dipres.gob.cl/572/articles-76544_doc_pdf.pdf>

Dirección de Presupuestos (2017): "Informe de Finanzas Públicas Proyecto de Ley de Presupuestos del Sector Público para el año 2018” Disponible en: < http://www.dipres. gob.cl/598/articles-166194_doc_pdf2.pdf>

ENDRESS, Sergio (2009) "Derecho presupuestario chileno: notas sobre sus actores, procedimiento y principios en la constitución”, Revista de Derecho Público, vol. 71: pp. 102116.

Engel, Eduardo, Marcel, Mario y Meller, Patricio (2007) "Meta de superávit estructural: elementos para su análisis" Disponible en: <http://www.dipres.gob.cl/572/articles-21746_doc_pdf.pdf>

FAGGiani, Valentina (2016) "La constitucionalización del "equilibrio presupuestario“: entre spending review y garantía del nivel mínimo de las prestaciones sociales" en García, Miguel, Asensi, José y Balaguer, Francisco (coords.), Constitucionalismo critico. Liber amicorum Carlos de Cabo Martín, tomo I, 2a edición (Valencia, Tirant lo Blanch): pp. 733-766.

Frankel, Jeffrey (2011): "Una solución a la prociclicidad fiscal: Chile, pionero en instituciones presupuestarias estructurales”, Economía Chilena, vol. 14, No 2: pp. 39-78.

Ffrench-Davis, Ricardo (2016): "La experiencia de Chile con el balance fiscal estructural", Cuadernos de Economía, 35 (67), número especial: pp. 149-171. 
GaLÁN, Javier (2014) "El enfoque de las reglas fiscales ante la discrecionalidad de la política pública” Economía Informa, No 388: pp. 50-67.

GarCíA, Gustavo (2012): "Reglas fiscales para la estabilidad y sostenibilidad”, en CorbACHO, Ana (coord.), Las instituciones fiscales del mañana (Washington, Banco Interamericano de Desarrollo) pp. 1-45.

GarCíA, Javier y MARTíneZ, Miguel (2013): Estabilidad presupuestaria y su consagración del freno constitucional al endeudamiento (Cizur Menor, Editorial. Thomson Reuters Aranzadi).

GuZMÁn, Marcela y Marcel, Mario (2008): "Hacia un círculo virtuoso en la reforma presupuestaria en Chile", Presupuesto y Gasto Público, No 51: pp. 305-323.

JiméneZ, Juan Pablo y López, Isabel (2013): "Política fiscal y reforma presupuestaria en América Latina”, Presupuesto y Gasto Público, No 73: pp. 25-47.

Larraín, Felipe (2010) “Estado de Hacienda Pública 2010” Disponible en: <http://www. hacienda.cl/documentos/estado-de-la-hacienda-publica/estado-de-la-hacienda-publica-2010.html>

Larraín, Felipe y Parro, Francisco (2008): “Chile menos volátil”, Trimestre económico, vol. LXXV (3) No 299: pp. 563-596.

Le ForT, Guillermo (2006): "Política Fiscal con meta estructural en la experiencia chilena” Disponible en: < https://publications.iadb.org/bitstream/handle/11319/6529/ Pol\%C3\%ADtica $\% 20$ fiscal $\% 20$ con $\% 20$ meta $\% 20$ estructural $\% 20$ en $\% 20$ la $\% 20$ experiencia $\% 20$ Chilena.pdf? sequence $=1>$

Marcel, Mario (2013): "The Structural Balance Rule in Chile: Ten Years, Ten Lessons" Disponible en: <http://services.iadb.org/wmsfiles/products/Publications/37889337. pdf>

Marcel, Mario y Vega, Alejandra (2010): “Los fondos soberanos y la política fiscal en Chile 2006-2010" Disponible en: < http://www.cieplan.org/media/publicaciones/archi$\operatorname{vos} / 314 /$ Paper.pdf>

Ministerio de Hacienda (2018a) "Informe Ejecutivo Mensual a Marzo de 2018 del Fondo de Reserva de Pensiones" Disponible en: < http://www.dipres.gob.cl/598/articles-173793_doc_pdf.pdf>

Ministerio de Hacienda (2018b) "Informe Ejecutivo Mensual a Marzo de 2018 del Fondo de Estabilización Económica y Social” Disponible en: < http://www.dipres.gob. cl/598/articles-173792_doc_pdf.pdf>

OBANDO, Iván (1994): "Observaciones acerca de la regulación de la ley de presupuesto en la Constitución Política de 1980 y sus normas complementarias", Revista de Derecho, XV: pp. 495-544.

Pallavicini, Julio (2015): Derecho Público Financiero (Santiago, Editorial Thomson Reuters).

Parrado, Eric, Rodríguez, Jorge y Velasco, Andrés (2012): "Responsabilidad fiscal en Chile: Propuestas para seguir avanzando”, Estudios Públicos No 127, invierno: pp. 89122.

Precht, Jorge (1993): "Principios Jurídicos de Hacienda Pública", Revista Chilena de Derecho, vol. 20, Nos. 2-3: pp. 775-794. 
RaE-Real Academia de la Lengua Española (2017) "Diccionario" Disponible en <http:// dle.rae.es/?id=YlD9xs3>

Rodríguez, Jorge y Flores, Lorena (2010): "Protección del gasto público social a través de la política fiscal: el caso de Chile”, Serie Financiamiento del Desarrollo, No 224: pp. 1-26.

RuIz, Violeta (2008): Estabilidad presupuestaria y gasto público en España (Madrid, Editorial La Ley).

SAFfirio, Camila (2012): "Regulación de fondos soberanos. El caso chileno", Anuario de Derecho Público UDP: pp. 569-584.

Ter-Minassian, Teresa (2011): "Should Latin American countries adopt structural balancebased fiscal rules?”, Revista de Economía y Estadística, vol. XLIX, № 1: pp. 115-143.

Velasco, Andrés (2009): "Estado de Hacienda Pública 2009” Disponible en: <http://www. hacienda.cl/documentos/estado-de-la-hacienda-publica/estado-de-la-hacienda-publica-2009.html>

Velasco, Andrés, Arenas, Alberto, Céspedes, Luis y Rodríguez, Jorge (2007): “Compromisos Fiscales y la Meta de Superávit Estructural” Disponible en: < http://www.dipres. gob.cl/594/articles-21645_doc_pdf.pdf>

Velasco, Andrés, Arenas, Alberto, Rodríguez, Jorge, Jorrat, Michael y Gamboni, Cristóbal (2010): "El enfoque de Balance Estructural en la Política Fiscal en Chile: Resultados, Metodología y Aplicación al período 2006 - 2009” Disponible en: <http://www. dipres.gob.cl/594/articles-60584_doc_pdf.pdf>

Yrarrázaval, Jaime (1987): "Principios económicos de la Constitución de 1980", Revista Chilena de Derecho, vol. XIV: pp. 97-112.

\section{NORMAS CITADAS}

Constitución Política de la República (24/10/1980).

LEY No 20.128 (30/09/2006), sobre responsabilidad fiscal.

Decreto Ley No 1.263 (28/11/1975), Orgánico de Administración Financiera del Estado.

Decreto Ley No 3.500 (13/11/1980), que establece nuevo sistema de pensiones.

Decreto con Fuerza de Ley No 1 (12/2/2007), del Ministerio de Hacienda, que refunde en un solo fondo los recursos adicionales de estabilización de los ingresos fiscales a que se refiere el Decreto Ley No 3.653, de 1981 y los del fondo de compensación para los ingresos del cobre, constituido conforme al Convenio de Préstamo BIRF No $2.625 \mathrm{CH}$, y fija la normativa para su operación.

Decreto Ley No 3.653 (14/3/1981), que establece precio de referencia del cobre.

Decreto No 1.259 (10/1/2007), del Ministerio de Hacienda, que establece las bases de la política fiscal de acuerdo a lo dispuesto en el artículo $1^{\circ}$ y $1^{\circ}$ transitorio, letra a), de la ley No 20.128 .

Decreto No 637 (26/6/2010), del Ministerio de Hacienda, que establece las bases de la política fiscal de acuerdo a lo dispuesto en el artículo $1^{\circ}$ de la ley № 20.128. 
Decreto No 1.357 (21/10/2011), del Ministerio de Hacienda, que modifica decreto No 637, de 2010, que establece las bases de la política fiscal de acuerdo a lo dispuesto en el artículo $1^{\circ}$ de la ley No 20.128 .

Decreto No 892 (3/7/2014), del Ministerio de Hacienda, que establece las bases de la política fiscal, de acuerdo a lo dispuesto en el artículo $1^{\circ}$ de la ley № 20.128 .

Decreto No 1.378 (5/10/2015), del Ministerio de Hacienda, modifícase el decreto supremo No 892, del 3 de julio de 2014, del Ministerio de Hacienda, que establece las bases de la política fiscal, de acuerdo a lo dispuesto en el artículo $1^{\circ}$ de la ley No 20.128.

Decreto No 1.247 (27/1/2018), del Ministerio de Hacienda, que deroga el decreto No 1.382, de 2006, modificado por el decreto No 1.649, de 2007, y fija normas, límites, procedimientos y controles para las inversiones de los recursos del Fondo de Reserva de Pensiones, creado por la ley $\mathrm{N}^{\circ} 20.128$

Decreto No 1.383 (17/2/2007), del Ministerio de Hacienda, que delega la representación del Fisco para la inversión de los recursos fiscales que indica, designa al Banco Central de Chile en carácter de agente fiscal, y modifica el decreto No 1.009, de 1978, del Ministerio de Hacienda.

Decreto No 1.492 (6/3/2015), del Ministerio de Hacienda, que reglamenta la coordinación y funcionamiento de las actividades de asesoría, apoyo a la gestión y fiscalización de los activos y pasivos financieros del tesoro público, en especial del Fondo de Estabilización Económica y Social y del Fondo de Reserva de Pensiones, y deroga decreto No 1.636 , de 2009.

Decreto No 621 (11/8/2007), del Ministerio de Hacienda, que crea Comité Financiero señalado en la ley No 20.128 .

Decreto No 1.251 (22/8/2014), del Ministerio de Hacienda, que modifica decreto No 621, de 2007, que crea comité Financiero señalado en la ley No 20.128.

Decreto No 545 (28/6/2013), del Ministerio de Hacienda, que crea Consejo Fiscal Asesor. Ordinario No 1.567, de 2015, del Ministerio de Hacienda.

\section{JURISPRUDENCIA CITADA}

Requerimiento de Senadores respecto del Decreto Supremo No 1.679, de fecha 31 de diciembre de 1996, del Ministerio de Hacienda, publicado en el Diario Oficial el 8 De febrero de 1997: Tribunal Constitucional Chileno, Rol No 254, 26 de abril de 1997.

Requerimiento de un grupo de Senadores respecto de la constitucionalidad de tres glosas contenidas en el proyecto de Ley de Presupuestos del Sector Público para EL AÑo 2011: Tribunal Constitucional Chileno, Rol No 1.867, de 30 de diciembre de 2010. 